\title{
Discovery Health's take on Regulation 8
}

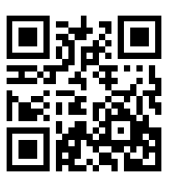

Dr Jonathan Broomberg, CEO of Discovery Health, and Milton Streak, the Principal Officer of the Discovery Health Medical Scheme, said both entities supported the Council for Medical Schemes (CMS) and did not agree with the Board of Healthcare Funders (BHF) in its view on Regulation 8. Discovery Health Medical Scheme and other schemes managed by Discovery Health had 'for several years, had payment arrangements in place allowing members' access to full payment for PMB [Prescribed Member Benefit] conditions'.

Broomberg painted a broader picture of healthcare inflation, saying it was due to a number of interacting factors including tariffs and other supply-side factors, as well as powerful demand-side factors that continuously drove up the usage of health services. 'Tariffs paid to doctors and hospitals increase at or just above CPI [consumer price index] levels on an annual basis. However, each year, the usage of healthcare services by scheme members increases by $3-4 \%$ due to the combination of ageing, higher chronic disease prevalence as well as new medicines and medical technology that often come onto the market at significantly higher costs than the medicines they replace. Thus, both tariffs and utilisation contribute to medical inflation, but our data show that utilisation is the more significant of these over the past several years.

\section{Cancer costs doubled in} last 3 years - Broomberg These trends were clearly shown by the costs of treating cancer. Total oncology spend for Discovery Health Medical Scheme increased by $17 \%$ from 2010 to 2011 (R872 million to R1.02 billion). The combination of higher treatment costs and higher rates of cancer incidence had doubled the costs of cancer treatments in the Discovery Health Medical Scheme over the past 3 years. Broomberg explained that the underlying market dynamics also contributed to healthcare inflation, with a 'serious and growing shortage of specialists, and some areas of market concentration in the supply of various services. More important than tariffs, however, were two fundamental features of the country's private healthcare delivery system - the fee for

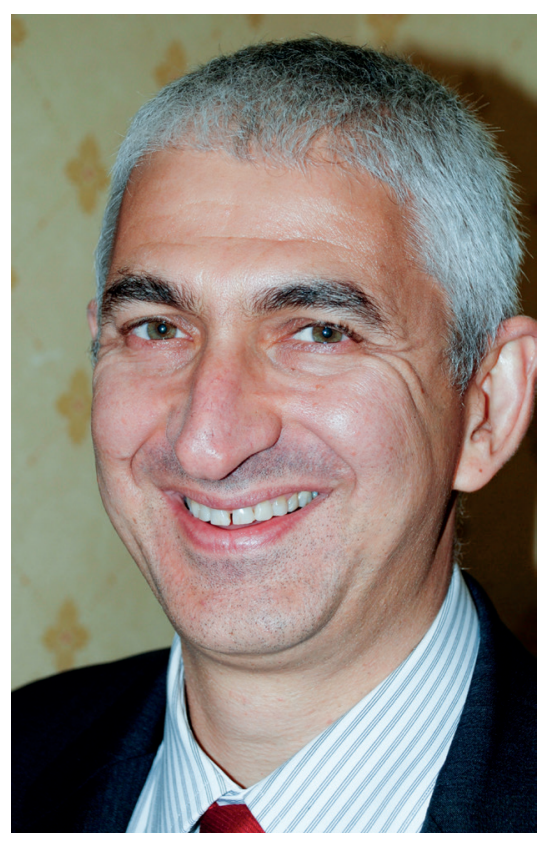

Dr Jonathan Broomberg, CEO of Discovery Health.

service payment system, and the fragmented structure in which doctors, hospitals and all other providers worked in silos with 'almost no coordination between them'.

'Our healthcare system needs to work to reduce waste and inefficiency at all levels. On the supply side, we need concerted action from funders, hospital groups and doctors to examine and work together on alternatives to fee-for-service, for example payment models that better align incentives for efficiency, and quality of care. Equally important is to move away from uncoordinated and fragmented healthcare delivery systems, towards integrated healthcare teams. None of this can be imposed by funders, however. These shifts must be led by the doctors and other health professionals working with medical schemes. We also need a shift away from general private hospitals towards more efficient hospital delivery models, including high-volume day surgery centres and specialised units using lean production approaches. More coordination between different healthcare providers and sharing of critical and vital medical information are critical elements to ensure efficiency in our healthcare system. On the demand side, medical schemes and employers must invest more in wellness approaches that address the burden of chronic diseases of lifestyle.'

\section{'Adverse selection' a major inflation driver}

In addition, South Africa's private healthcare system faced some 'unique' demand-side challenges, which added fuel to the inflation fire. 'Our medical scheme legislation is laudably egalitarian; it is based on open enrolment and community rating - medical schemes must accept all applicants regardless of age and health status - and schemes must charge the same premium for all members in each option, regardless of health status or age. While these laws are common in many global health insurance systems, and highly effective in protecting individuals against discrimination based on their health risks, they are almost universally implemented in conjunction with a legal mandate for all eligible individuals to take out health insurance. Only South Africa enforces open enrolment and community rating, but allows scheme membership to remain voluntary. This unbalanced arrangement leads to a significant problem of "adverse selection" against medical schemes - the young and healthy join a scheme only when they believe they will really need healthcare, and new joiners typically join lower benefit options, and "buy up" to higher plans only if they become ill.'

\section{'Both tariffs and utilisation} contribute to medical inflation, but our data shows that utilisation is the more significant of these over the past several years.' - Jonathan Broomberg

These factors contributed significantly to healthcare inflation by driving high annual increases in the usage of services by the average scheme member, while medical schemes increasingly lost out on the surplus funds generated by the young and healthy - which they 'desperately needed' to fund the higher claims of the elderly and the sick, further driving up medical scheme premiums.

\section{Chris Bateman}

chrisb@hmpg.co.za

S Afr Med J 2013;103(12):887.

DOI:10.7196/SAMJ.7692 